This is an electronic reprint of the original article. This reprint may differ from the original in pagination and typographic detail.

Please cite the original version: A. Kultavirta, P. Marjanen (2018) The Subjectice Well-Being of Children Internationally and in Finland, ICERI2018 Proceedings, pp. 1016-1020.

doi: $\underline{10.21125 / \text { iceri.2018.1237 }}$ 


\title{
THE SUBJECTIVE WELL-BEING OF CHILDREN INTERNATIONALLY AND IN FINLAND
}

\author{
A. Kultavirta, P. Marjanen \\ Laurea University of Applied Sciences (FINLAND)
}

\begin{abstract}
The concept of child well-being has been studied in a variety of disciplines. However, the well-being of children is often based on the experience of parents, professional assessments or health surveys. The voice of children and the subjective experience of their well-being is often missing. We need more research and indicators of children's subjective well-being.

Services for children and families are being reformed in the Finnish Government's key project, Programme to Address Child and Family Services (LAPE). Laurea University of Applied Sciences is studying the experimental well-being data of small children in the project and is developing the subjective well-being indicator for children. In this article, the authors consider why children's subjective well-being information is needed and what should be known about the subjective well-being of children. The aim of the research is to discuss the essential considerations when assessing the subjective wellbeing of children.
\end{abstract}

Keywords: Child, well-being, subjective well-being, child research, well-being indicators.

\section{INTRODUCTION}

The further development of well-being indicators is topical in Finland and internationally. International objective well-being indicators are numerous, largely based on health care data [1] .Societal concerns about the well-being of children have increased and the need to measure subjective well-being information has been raised internationally; validated well-being indicators and further development are needed ([2], [3], [4], [5], [6]). There is political will and data collected through subjective well-being indicators could also be used to support political decisions ([4], [6]).

Collecting information, especially in the case of children, is still quite inadequate. The well-being of children is a relatively new and challenging research area ([6], [7]). Objective indicators of well-being for children alone do not provide a reliable picture of the well-being of young children; subjective indicators are needed as well ([6], [8]).

In the Ministry of Social Affairs and Health's key project LAPE, Laurea University of Applied Sciences is studying the subjective well-being of children between the ages of five and eight. On the basis of the information collected in the research, the aim is to develop a playful well-being indicator to support the well-being of children and families by collecting children's subjective well-being data. We have now begun developing a playful well-being indicator for young children. The intention is to continue the research and development work.

The voice of small children is seldom heard from the perspective of subjective wellbeing; the experiences of small children have not been measured much [8]. In developing a new indicator, it is essential to analyze existing ways of collecting wellbeing data and to gather an understanding of what the well-developed indicators are 
based on and how they should be developed further to fit national needs. The aim of the research is to discuss the essential considerations when assessing the subjective well-being of children.

\section{CHILD WELL-BEING}

Well-being is commonly understood as a wide-ranging and multidimensional phenomenon that includes a number of interrelated and controversial issues. These entities can be thought of as dimensions of prosperity. Determining well-being is not one-selectable, and there is disagreement about which themes or subsectors create the basis of well-being [9]. National definitions and priorities may also vary greatly. For example, definitions have links to existing national policy programmes, to the nature of the services and to the cultural understanding of the family and its structure [1]. In the OECD and UN documents, child well-being is identified as an important issue ([10], [11]). and finding the most suitable indicators to measure the well-being of children is particularly important ([12], [13]).

There has long been an objective perspective in the study of well-being that seeks measurable factors, such as life expectancy, financial status or literacy. Another way of looking at the prosperity of approaching the phenomenon is a subjective perspective. In this approach, people are asked about their experiences and there is an attempt to understand their well-being more deeply. The emphasis is on individual feelings and thoughts ([14]). Subjective well-being is a qualitative concept that consists of several sub-areas and because the concept is complex there is no consensus on a definition. However, well-being research has been able to classify areas of well-being [15]. In examining a subjective approach in research, attention has been paid especially to psychological well-being as it is a major contributor to the well-being experience. It is observed that psychological well-being, according to studies, also leads to other aspects of well-being, such as economic, as Diener's studies show ([16], [17]). There are also other approaches and emphases to well-being research. One example is cultural diversity and flexibility, which is understood as the ability of culture to maintain and develop cultural identity, knowledge and practices. The importance of culture is stressed by emphasising people's values, responding to spiritual and emotional needs, curbing the pace of modernisation and the negative impacts of globalisation, securing and strengthening the sovereignty and security of the country and promoting diversity.

It is remarkable that there is no research-based understanding of how children understand their own well-being and see themselves as participants in their own lives. The use of subjective research methods and data is inadequate. There are several research aspects for defining the matter. Schues and Rehmann-Sutter have a philosophical and holistic research perspective on the topic. They define child wellbeing in connection with the child's physical, mental, personal, cultural and social development, which leads to a meaningful life with other people [18]. The structural but also societal approach is represented by Minkkinen's theoretical model, outlining the well-being of the child from physical, psychological, social and material dimensions [19]. She emphasises the positive elements of well-being more than the negative and related subjective wellness research. Konu, meanwhile, has developed a model for evaluating children's school environments and their well-being. In this model, children's well-being indicators are divided into four categories: schooling, social relationships, self-realisation and health. Marshford-Scott et al. argue the views on children's wellbeing review are: social and economic, psychological and mental health, philosophical 
and educational [8]. However, there is not much research data on the well-being of children.

\section{METHODOLOGY}

When developing a new subjective well-being indicator, it is necessary to thoroughly study the existing research literature already on the subject. Through the literature review, we aim to develop a holistic picture of children's well-being research and the development perspective of well-being indicators. A literature review was selected for the narrative review. The aim of the narrative review is to find out, through international research literature, the factors to be taken into account in the measurement of subjective well-being of children. The research question was to answer what the essential considerations are when assessing the subjective well-being of children.

Conducting a literature review is not easy and reflection and a common dialogue are needed, among other things, for the selection criteria for a literature review. The review material consisted of eight research articles. In order to obtain up-to-date information on the subject, we limited our search to information from the years 2008-2018. The articles selected for the review were analysed by content analysis. Several articles were found on many search engines.

Several searches were initially conducted and the search results, despite the limited scope, are extensive. At first, the keywords were 'children', 'welfare', 'subjective wellbeing', well-being', 'happiness' and 'indicator'. This search was limited to English research articles. Despite the limitations, the resultswere extensive, and Google Scholar, for example, yielded 17,300 hits".

Then we added 'systematic review' to the keywords as well to the search command. In another search, Google Scholar's search result was 1980 hits. The literature review was based on the following criteria: the article deals with the well-being of children, subjective well-being and well-being indicators. On the basis of these limitations, a closer look at the 30 articles was carried out at the headline and abstract level, after which the eight selected articles were examined on the basis of the whole text and a content analysis on the basis on that was begun.

\section{RESULTS}

In the narrative literature review, the following eight research articles were selected: Dex \& K. Hollingworth. Children's and young people's voices on their wellbeing [2] , Savahl, Adams, Isaacs, September, Hendricks \& Noordien. Subjective Well-Being Amongst a Sample of South African Children: A Descriptive Study [3], Dodge, Daly, Huyton \& Sanders. The challenge of defining wellbeing [4], Bradshaw, Martorano, Natali \& de Neubourg. Children's Subjective Well-Being in Rich Countries. Child Indicator Reasearch [5], Casas. Subjective Social Indicators and Child and Adolescent [6], Fattore, Mason \& Watson. When Children are Asked About Their Well-being: Towards a Framework for Guiding Policy [7], Mashford-Scott, Church \& Tayler. Seeking Children's Perspectives on their Wellbeing [8], Minkkinen. The Structural Model of Child Well-Being. Child Indicators Research [19]. 
These were subjected to a content analysis in response to the research question: What are the essential considerations when assessing the subjective well-being of children through the content analysis, eight themes were found. Table 1 describes the themes that were formed in response to the research question. In addition, Table 1 shows where the themes have been dealt with.

Table 1. Narrative literature review and themes

\begin{tabular}{|c|c|c|c|c|c|c|c|c|}
\hline & 1.Casas & 2.Fattore & 3.Marshford & 4.Dodge & 5.Minkkinen & 6.Bradshaw & 7.Savahl & 8.Dex \\
\hline $\begin{array}{l}\text { wellbeing } \\
\text { information } \\
\text { and } \\
\text { indicators }\end{array}$ & $X$ & & $X$ & & $X$ & & & $X$ \\
\hline $\begin{array}{l}\text { Defining } \\
\text { wellbeing }\end{array}$ & $X$ & & $X$ & $X$ & $X$ & & & \\
\hline $\begin{array}{l}\text { Methods of } \\
\text { data } \\
\text { collection }\end{array}$ & $x$ & $x$ & $x$ & & & & $x$ & $x$ \\
\hline $\begin{array}{l}\text { Differences } \\
\text { in wellbeing } \\
\text { - children } \\
\text { and adults }\end{array}$ & $X$ & $X$ & & & & & & $X$ \\
\hline $\begin{array}{l}\text { Children as } \\
\text { answerer } \\
\text { and cultural } \\
\text { differences }\end{array}$ & & $X$ & & $X$ & & $X$ & & $X$ \\
\hline $\begin{array}{l}\text { Language } \\
\text { and } \\
\text { Interpretation }\end{array}$ & & & $X$ & & & & & $X$ \\
\hline $\begin{array}{l}\text { The history } \\
\text { of wellbeing }\end{array}$ & & & & $X$ & & & & \\
\hline Ethics & & & $X$ & & & & & \\
\hline
\end{tabular}

Table 1 the first theme is Well-being information and indicators. The subjective experiences of small children about their own well-being are not sufficiently taken into account. Objective well-being indicators are largely based on the conclusions of parents and adults on the well-being of children. Subjective well-being indicators are needed for reliable well-being information. International data on children's well-being is missing. There is a social concern about children's well-being, and subjective wellbeing in particular should be measured. International comparable welfare indicators need to be further developed and more research is also needed ([2], [8], [19]).

Table 1 the second theme is Defining well-being. Well-being is a growing and new research area and defining it is a major challenge due to multidisciplinarity. Currently, different disciplines have different definitions and contradictory views about what is meant by well-being. Defining well-being requires a common understanding and a 
more general theoretical framework, in which its actualization and measurement are facilitated. Well-being as a concept is wider than happiness and subjective well-being includes life satisfaction, positive effects and negative impacts ([4], [6], [8], [19]).

Table 1 the third theme is Methods of data collection. For small children, it is important to focus on research-based solutions in the development of well-being indicators. Research methods that involve children are needed for data collection and for each phase of the study. A well-constructed survey offers children the opportunity to respond when adult-prepared pre-coded questions may not reach children. It is good to ask children open and semi-structured questions. Identifying the subjective research challenges for young children and investing in qualitative research in particular is essential in development work. Discussions, interviews and drawing are methods that are very suitable for children. It is important to try to avoid any assumptions made by researchers ([2], [3], [6], [8], [13]).

Table 1 the fourth theme is Differences in well-being in the case of children and adults. The way in which children and adults define and interpret well-being are different. The subjective answers of children may differ essentially and they can give different meanings to well-being. We need children's subjective perceptions and evaluations about their own well-being as well as objective evaluations ([2], [6], [13]).

Table 1 the fifth theme is Children as respondents and cultural differences. The age differences of children, gender, personality, maturity, social dimension and socioeconomic background affect how children respond concerning their well-being. For example, age-grading questions are needed, which serve as reliable indicators. There are also differences between cultures when it comes to what is included in the best possible life ([2], [4], [5], [13]).

Table 1 the sixth theme is Language and Interpretation. Children interpret adult's questions differently and may not necessarily understand them in the same way. The language challenges can be seen in two-way. Children are also affected by the time and space of a questionnaire, including the ability of individual children to respond. Small children do not understand well-being as a concept, and the formulation of the survey questioning involves many challenges ([2], [8]).

Table 1 the seventh theme is the history of well-being. Understanding the history of well-being and its definition is essential. The Hedonic tradition emphasised structures and satisfaction with life, the tradition of Aristotle's eudaimony emphasised positive psychological activity and human development. Today, there is an understanding of well-being as a multi-dimensional structure, which also creates a controversial research base [4].

Table 1 the eighth theme is Ethics. In measuring the subjective well-being of young children, ethical issues have to be emphasised [8].

\section{CONCLUSIONS}

The need for well-being information from small children is well understood, but its systematic subjective measurement is missing in practice. There is a need for comparable well-being data, particularly national data and common ways of measuring; thereby collecting valuable subjective well-being information on individual children, the individual group of children, the region and nationwide. The data collection should be systematic and should also be used in the decision-making of families with 
children. Subjective-based and objective-based indicators are needed to achieve a comprehensive understanding of the status of children's well-being. Based on the data, it is possible to identify what specific support measures or necessary interventions should be specifically targeted, which may also be group-specific. There is a need for data-based subjective and objective well-being in support of policy-makers to focus on family-oriented services, as well as parents to support their day-to-day and educational tasks.

Identifying well-being information is also necessary. It would be valuable if we could address the answers of a single child if, for example, it would lead to serious lack of well-being and possibly even a child protection need. In addition to individual wellbeing information, group-specific and, for example, municipalities-specific information are required. Group-specific data could be targeted specifically at the target group for interventions in needed.

In the development of well-being indicators, it should be noted that it is not only an instrument of assessment when it could possibly prevent access to information for individual children. Privacy issues and ethical issues are also important, especially for young children. Ideally, we would also be able to compare well-being information internationally and share well-functioning models of intervention to be further tailored to national needs. There is a need for extensive international scientific networking dialogue. It is critical that we think about how to respond to well-being problems and how multiprofessional cooperation in supported to increase well-being for children and families. More commitment and commitment in leadership is needed to further strengthen multi-professional co-operation and to find a common understanding.

As part of the LAPE project, we have preliminarily considered subjective well-being indicators that would be suitable for small children and piloted suitable methods of data collection. The approach was holistic as we used the four dimensions of well-being developed by Minkkinen: psychic, physical, social and material. ([20]). More research on well-being indicators is still needed.

This literature review reveals that on the basis of a wide range of research, no subjective well-being indicators have been developed internationally for children aged five to eight years. Knowledge and analysis of existing objective well-being indicators are needed to develop a new subjective well-being indicator.

\section{REFERENCES}

[1] P. Marjanen, A. Ornellas \& L. Mäntynen, Determining Holistic Child Well-being: Critical Reflections on Theory and Dominant Models. Child Indicators Research, Volume 10,Issue 3, pp 633-647, 2017.

[2] S. Dex \& K. Hollingworth. Children's and young people's voices on their wellbeing. CWRC WORKING PAPER No. 14, 2012.

[3] S. Savahl, S. Adams, S. Isaacs, R. September, G.Hendricks \& Z. Noordien. Subjective WellBeing Amongst a Sample of South African Children: A Descriptive Study. Child Indicators Research The official Journal of the International Society for Child Indicators, 2015. ISSN 1874897X Child Ind Res DOI 10.1007/s12187-014-9289-8 
[4] R. Dodge, A.P. Daly, J. Huyton \& L.D. Sanders. The challenge of defining wellbeing. International Journal of Wellbeing,2012. 2(3), 222-235. doi:10.5502/ijw.v2i3.4

[5] J. Bradshaw, B. Martorano, L. Natali \& C. de Neubourg. Children's Subjective Well-Being in Rich Countries. Child Indicator Reasearch. Volume 6, Issue 4, pp 619-635, 2013.

[6] F. Casas. Subjective Social Indicators and Child and Adolescent Well-being. Child Ind Res , 2011. 4:555-575 DOI 10.1007/s12187-010-9093-z.

[7] T. Fattore, J. Mason \& E. Watson. When Children are Asked About Their Well-being: Towards a Framework for Guiding Policy. 3008 Child Indicators Research; Dordrecht Vol. 2, Iss. 1, 2009. 57-77. DOI:10.1007/s12187-008-9025-3

[8] A. Mashford-Scott, A. Church \& C. Tayler. Seeking Children's Perspectives on their Wellbeing, 2012.

[9] J. Saari. Hyvinvointi. Suomalaisen yhteiskunnan perusta. pp 9, 2011. Helsinki: Gaudeamus.

[10] OECD. Doing Better for Children. Paris: OECD. 2015.

[11] UNICEF. Child poverty in perspective: an overview of child well-being in rich countries .2007. Innocenti report card 7, Florence.

[12] A. Ben-Arieh. Developing indicators for child Well-being in a changing context. in McAuley, C. \& Rose, W. (eds.) 2010. Child Well-Being: Understanding Children's lives. Lontoo: Jessica Kingsley publishers, 129-142.

[13] T. Fattore, J. Mason \& E. Watson Children's conceptualition(s) of their well-being. Social Indicators research, 5-29. 2007.

[14] E. Alatartseva \& G. Barysheva G. Well-being: Subjective and Objective Aspects. Procedia Social and Behavioral Sciences 166, 36-42.2015.

[15] Törrönen. Onni on joka päivä. Lapsiperheen arki ja hyvinvointi. Helsinki: Gaudeamus, pp 33, 2012.

[16] E. Diener \& S. Oishi. Money and Happiness: Income and Subjective Well-being across Nations. In E. Diener \& E. M. Suh (eds.) Culture and subjective wellbeing. 2003

[17] L. Tay \& E. Diener. Needs and Subjective Well-Being Around the World. Journal of Personality and Social Psychology, Vol. 1010, No. 2; 354-365. 2011.

[18] C. Schües \& C. Rehmann-Sutter. The Well- and Unwell-Being of a Child. Topoi. Volume 32, Issue 2, pp 197-205, 2013.

[19] J. Minkkinen. The Structural Model of Child Well-Being. Child Indicators Research. Volume 6, Issue 3, pp 547-558, 2013. 